\title{
Tickling the TLR7 to cure viral hepatitis
}

\author{
Emily Funk', Shyam Kottilil², Bruce Gilliam ${ }^{3}$ and Rohit Talwani ${ }^{3 *}$
}

\begin{abstract}
Chronic hepatitis B and C are the leading causes of liver disease and liver transplantation worldwide. Ability to mount an effective immune response against both HBV and HCV is associated with spontaneous clearance of both infections, while an inability to do so leads to chronicity of both infections. To mount an effective immune response, both innate and adaptive immune responses must work in tandem. Hence, developing protective immunity to hepatitis viruses is an important goal in order to reduce the global burden of these two infections and prevent development of long-term complications. In this regard, the initial interactions between the pathogen and immune system are pivotal in determining the effectiveness of immune response and subsequent elimination of pathogens. Toll-like receptors (TLRs) are important regulators of innate and adaptive immune responses to various pathogens and are often involved in initiating and augmenting effective antiviral immunity. Immune-based therapeutic strategies that specifically induce type I interferon responses are associated with functional cure for both chronic HBV and HCV infections. Precisely, TLR7 stimulation mediates an endogenous type I interferon response, which is critical in development of a broad, effective and protective immunity against hepatitis viruses. This review focuses on anti-viral strategies that involve targeting TLR7 that may lead to development of protective immunity and eradication of hepatitis $\mathrm{B}$.
\end{abstract}

Keywords: Hepatitis C, Hepatitis B, Toll-like receptors, TLR7, Hepatitis treatment

\section{Introduction}

Defense against chronic viral infections is complex and involves both host innate and adaptive immune systems [1]. The major characteristic of the human immune system is the nature by which immune cells recognize self from non-self [2,3]. While the adaptive immune system features specific antigen recognition receptors, the innate immune system utilizes a unique set of pattern recognition receptors (PRRs), such as TLRs, which recognize non-specific, but conserved molecular structures on microorganisms [3-5]. However, certain viral pathogens such as hepatitis B (HBV) and C (HCV) may effectively evade host immune responses, thereby establishing chronic persistent infection [6,7] These infections can be treated with modest success using immunomodulatory therapy such as exogenous interferon [8-10]. Hence, there is a continued interest in other novel immune-based therapies for chronic viral hepatitis, which may improve treatment outcomes. Activation of specific TLRs results

\footnotetext{
* Correspondence: rtalwani@ihv.umaryland.edu

${ }^{3}$ Institute of Human Virology at the University of Maryland School of Medicine, 725 West Lombard St. N151, Baltimore, MD 21201, USA Full list of author information is available at the end of the article
}

in an endogenous interferon response leading to the production of antiviral, proinflammatory and costimulatory cytokines, enabling crosstalk between the innate and adaptive immune systems, which culminates in the stimulation of immune effector cells integral to antiviral immunity [11,12]. In this regard, interactions between viruses and TLRs may play a major role in developing protective antiviral immunity. Therefore, exogenous activation of TLRs represents an attractive therapeutic strategy to combat chronic viral pathogens such as HBV and $\mathrm{HCV}$.

\section{Review}

The toll-like receptor family

Members of the TLR family detect a wide range of conserved pathogen-associated molecular patterns (PAMPs). Upon recognition and binding to a PAMP, stimulation induces shared signaling pathways that culminate in expression of numerous host defense genes. In humans, there are 10 known members of the TLR family, which are membrane-bound proteins structurally characterized by the presence of a conserved intracellular Toll/interleukin (IL)-1 receptor (TIR) domain and 
leucine-rich repeat ectodomain $[13,14]$. This extracellular/ endosomal leucine-rich domain plays a key role in the binding of ligands, although the molecular basis for the recognition of the PAMPs by TLRs is largely unknown [15]. The TLR subgroups are classified according to the location of the receptor and its function upon activation. TLRs expressed on the cell surface include TLR1, TLR2, TLR4, TLR5 and TLR6; these subgroups are able to detect bacterial and fungal cell wall components and some viral proteins [16]. The intracellular subgroups TLR3, TLR7, TLR8, and TLR9 are located within endosomes and bind to viral nucleic acids $[16,17]$. Their location within endosomes provides an environment in which host DNA should not be present, thus avoiding the possibly deleterious effects of self-recognition [18]. TLR3, TLR 7/8 and TLR9 recognize viral or synthetically derived double stranded RNA, viral single stranded RNA or bacterial unmethylated CpG DNA, respectively [17,19-21]. While both TLR7 and 8 have similar structures, are triggered by viral single stranded RNA, and propagate signaling via the same adapter protein, the myeloid differentiation primary-response protein (MyD88, see below), their activation appears to result in different host cell responses. Interestingly, recent studies show a vital role of TLR7 activation in early immune responses and throughout progression of plasmodial infections, another pathogen with a liver life cycle [22]. Studies utilizing synthetic agonists demonstrated higher type I interferon induction by TLR7 signaling and greater proinflammatory cytokine induction via TLR8 activation [23]. In this review, we will focus primarily on TLR7, as the majority of small molecule TLR agonists undergoing clinical development for treatment of viral hepatitis target TLR7 agonists to induce an endogenous interferon response.

\section{TLR7 signaling: induction of antiviral cytokines}

TLR7 signaling is primarily associated with generation of an endogenous type I interferon response (Figure 1). Binding of TLR7 to its respective ligand causes conformational changes and dimerization of the receptors, followed by the recruitment of its specific TIR adaptor protein, MyD88. MyD88 activates a series of signal transduction molecules,

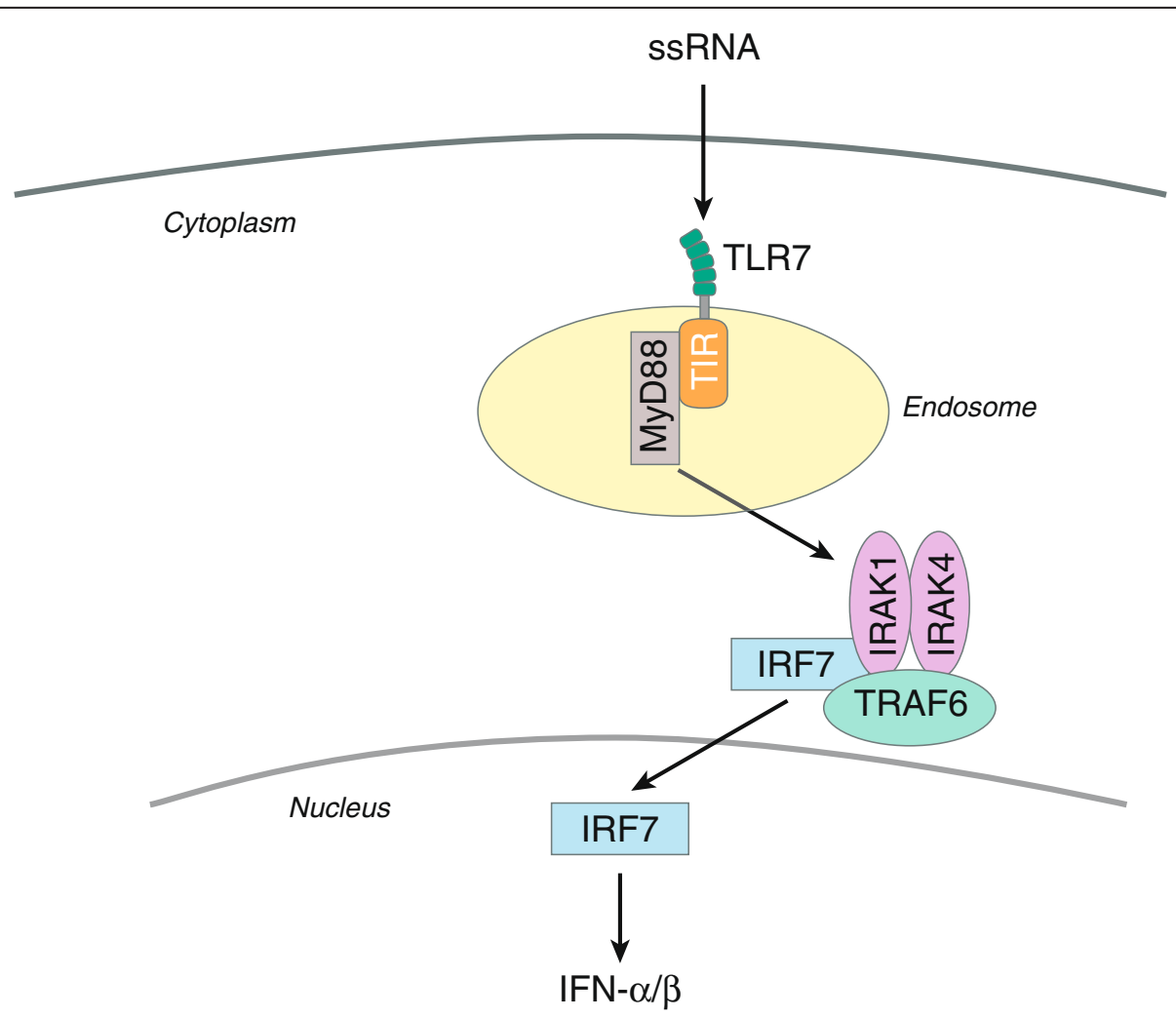

Figure 1 Selective TLR7 signaling. Natural ligands of TLR7 include ssRNA, particularly viral particles (HCV). Once an HCV virion enters the hepatocyte, it engages the TLR7 receptor resulting in the formation of a complex facilitated by the recruitment of adapter protein, MyD88 and $\mathrm{TIR}$, which occurs in the endosomal compartment. This complex then triggers a series of signal transduction pathways culminating in the formation of IRAK/IRF7/TRAF6 complex. IRF7 will translocate to the nucleus and transactivate the production of type I interferons (IFN-a and $\beta$ ). Exclusive TLR7 agonists generate activation of type I interferons, while TLR7/8 agonists result in the generation of proinflammatory cytokines, such as IL-2, IL-8, and TNF along with interferon $a / \beta$, which may result in development of undesirable adverse events. Hence, selective TLR7 agonists are ideal in the treatment of hepatitis viruses. 
including IL-1R associated kinases (IRAKs), tumor necrosis factor receptor (TNFR)-associated factor 6 (TRAF6), and transforming growth factor (TGF)-B activated kinase (TAK1), which yield activation of the transcription factors nuclear factor kappa B (NF-kB) and IFN regulatory factor 7 (IRF7) (Figure 1). TLR7 signaling is biased toward IRF7 activation, which facilitates production of antiviral cytokines, including type I and type II interferons, while NF-KB induces a proinflammatory effect via secretion of cytokines such as TNF- $\alpha$, interleukin- 6 and interleukin-12 (IL-6, IL-12) [16,18,24].

TLR7-induced production of type I and II interferons activate pathways that lead to the destruction of intracellular pathogens, including stimulation of adaptive immune effector cells [12]. This augmentation of innate and adaptive immune signaling makes TLR ligands an attractive addition to antiviral therapeutics [25]. However, immune activation can be a double-edged sword; exogenous immunomodulatory treatment must be utilized with caution in patients with cirrhosis as profibrogenic chemokine stimulation can activate hepatic stellate cells, which may exacerbate fibrosis.

\section{Linking innate and adaptive immunity: TLR-controlled $D C$-mediated activation of $T$ cells}

As a first line of defense, innate immune responses prime the adaptive immune system to mount an effective pathogen specific immune response. Efficient priming of adaptive immune response requires antigen presentation by the major histocompatibility complex (MHC) on antigenpresenting cells (APCs) in addition to the simultaneous induction and presentation of accessory signals, including several instructive cytokines and/or costimulatory molecules induced by innate immune signaling pathways. Dendritic cells (DCs) are professional antigen-presenting cells in humans. DC subsets respond to pathogens for which they have corresponding TLRs. In humans, TLR7 is expressed on plasmacytoid DCs (pDCs) and in some studies has also been detected on myeloid DCs (mDCs) [12]. The generation of adaptive immunity is dependent upon the maturation of DCs, a process that is mediated in various ways by TLR signaling [12,26,27]. This process begins with the recognition and sequestration of antigen by DCs in peripheral tissue and the subsequent migration to lymph nodes for presentation to naïve T lymphocytes [26] (Figure 2).

Once inside the lymph nodes, DCs seek out naïve antigen-specific $\mathrm{T}$ cells and induce their activation and differentiation into effector cells. The first signal in activation of naïve $T$ cells is an antigen-specific signal resulting from the binding of the $\mathrm{T}$ cell receptor to the peptide presented by the MHC molecule [26]. The second signal in activation is driven by costimulatory molecules CD80 and CD86 expressed on the DCs, which interact with $\mathrm{CD} 28$ on naïve $\mathrm{T}$ cells to stimulate $\mathrm{T}$ cell proliferation, cytokine production and generation of CTL response $[12,28]$. This is an example of TLR-mediated control of adaptive response, as hepatic $\mathrm{pDC}$ subsets upregulate costimulatory molecules CD40, CD80 and CD86 by TLR4, TLR7 and TLR9 stimulation [29,30]. Specifically, viral ssRNA (a PAMP), is delivered to and is endocytosed by a $\mathrm{pDC}$, and forms the source of the PAMP. Next, engagement of TLR7 on the endosome triggers the signaling pathways resulting in production of specific cytokines and costimulatory molecules that augment adaptive immune responses (Figure 2) [27,31]. Hence, TLR-mediated signaling impacts adaptive immune responses by producing cytokines that mediate $\mathrm{T}$ cell differentiation. In the liver, pDCs produce IFN- $\alpha$, TNF- $\alpha$, IL- 6 and IL- 12 in response to ligands for TLR7/9 $[29,32]$. Consequently, in response to stimulation by a TLR7 agonist, cytokines such as IL-12 drive the induction of $\mathrm{T}_{\mathrm{H}} 1$ responses on $\mathrm{T}$ cells [33], which is characterized by the production of IFN- $\gamma$ by $\mathrm{T}$ cells and further activation of cell-mediated immunity, resulting in the activation of phagocytes, antigen-specific cytotoxic $\mathrm{T}$ lymphocytes and the release of various cytokines (Figure 2).

Studies using animal models that lack TLR signaling pathways have clearly established the vital role played by TLR7 in antiviral immunity [11,34]. Mice deficient in MyD88, the adaptor protein that mediates signal transduction by TLR7, are not capable of signaling through TLRs. As a result, their APCs are not stimulated by TLR agonists [35]. MyD88-deficient mice demonstrated a lack of T cell activation in response to antigen, suggesting impairment in the antigen-specific priming of T cells [27]. Consequently, these mice failed to produce detectable amounts of IFN- $\gamma$ in response to antigen stimulation [27], suggesting that in the absence of TLR signaling, immune responses are severely impaired and unable to generate an effective $\mathrm{T}_{\mathrm{H}} 1$-dependent immune response. In addition, MyD88-deficient DCs treated with antigen did not induce production of CD80, CD86, MHC class II or IL-12, which resulted in an inability of DCs to mature and led to inefficient priming of naïve $\mathrm{T}$ cells [27]. These results support the theory that innate immune recognition by TLRs is required for induction of accessory signals required for the activation of adaptive immune response and inducing $\mathrm{T}_{\mathrm{H}} 1$ polarization by expressing IL-12 on APCs [27,36], an event critical for the induction of DC maturation, the generation of $\mathrm{T}_{\mathrm{H}}$ subsets and the activation of the adaptive immune response against viruses.

\section{Hepatitis C infection}

An estimated 4.1 million people are infected with hepatitis C (HCV) in the United States, with up to 180 million people infected worldwide [37,38]. Approximately 60-85\% of individuals infected with HCV will eventually develop chronic hepatitis $C$ infection [39-41]. Although chronic infection is usually asymptomatic, it can lead to 


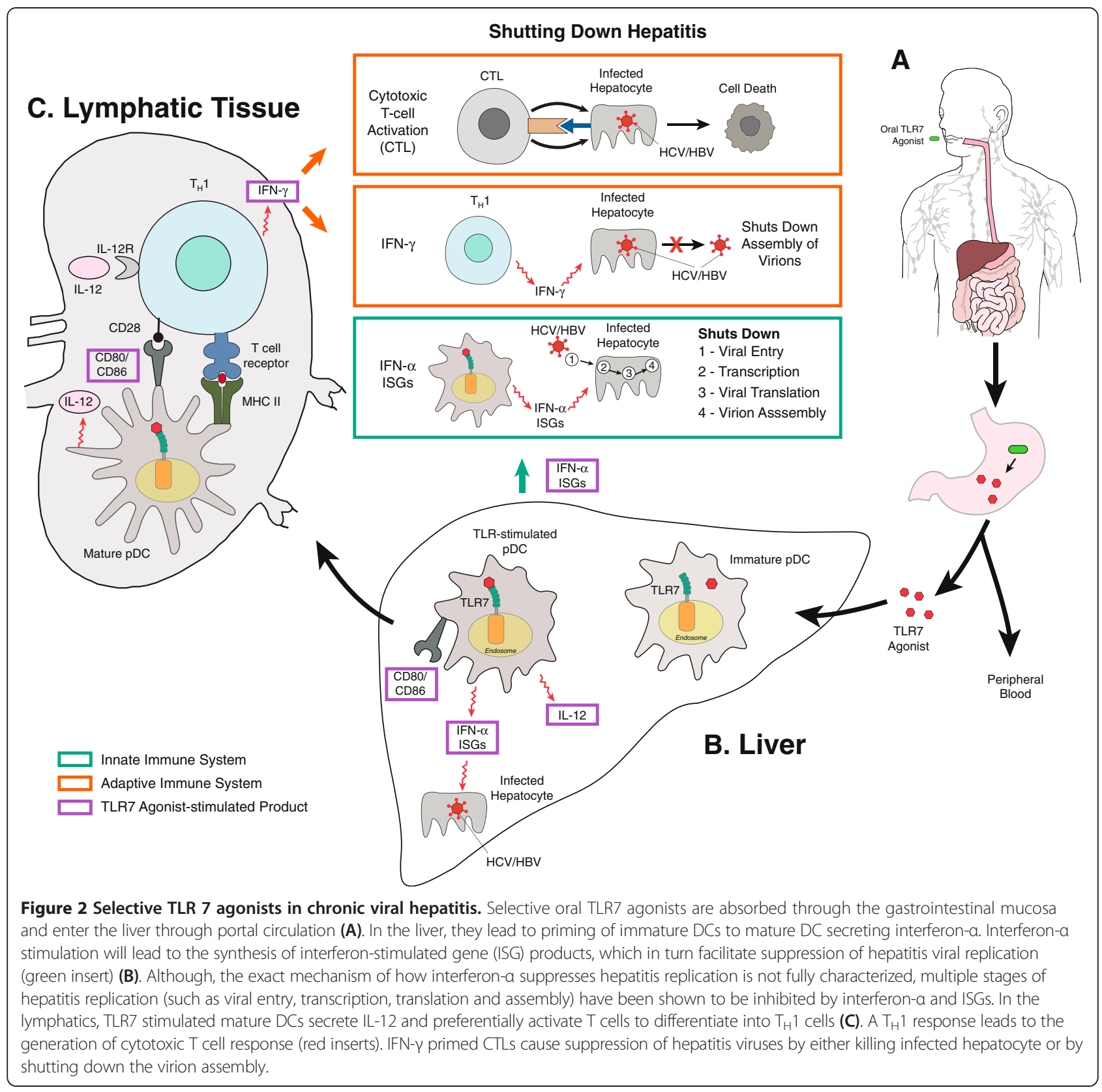

chronic liver disease, including cirrhosis, hepatocellular carcinoma and ultimately liver failure $[37,42]$. In the United States, complications from $\mathrm{HCV}$ are the leading indication for liver transplantation [43]. Currently, immunebased therapies including interferon still have a role in the eradication of HCV. The standard of care for $\mathrm{HCV}$ is rapidly evolving as safer, more effective therapies become available. Currently, the preferred regimen for $\mathrm{HCV}$ genotype 1 infection is a 12-week course of sofosbuvir (an HCV NS5B polymerase inhibitor) in combination with pegylated interferon and ribavirin [44], which resulted in a 90\% sustained virological response in phase III clinical trials [45]. The treatment paradigms will likely evolve to include interferon-sparing treatment options for most patients over the next few years.

\section{Plasmacytoid dendritic cells and TLR signaling in HCV infection}

Many viruses have evolved mechanisms to subvert host immune responses and $\mathrm{HCV}$ is no exception. The $\mathrm{HCV}$ NS3/4A protease inhibits TLR3 and RIG-I mediated signaling in infected hepatocytes [46], thereby blunting type I interferon responses in these cells. The robust induction of interferon stimulated genes (ISGs) in the livers of $\mathrm{HCV}$-infected patients [23] suggests that cells other than infected hepatocytes may drive type I interferon 
induction. In vitro work done in Huh 7.5 cells suggest that pDCs in HCV-infected livers stimulate type I interferon via TLR7 signaling without becoming infected [47]. Thus, cell-cell interaction should be required in order for pDCs to endocytose HCV RNA particles from infected hepatocytes. Recent work suggests that this cell-cell recognition is facilitated by CD81/CD9 tetraspanins [48]. In summary, these data suggest that TLR7 mediated signaling plays an important role in immune responses in $\mathrm{HCV}$-infected patients, and that exogenous TLR7 agonists may have a role in management of chronic HCV infection.

\section{TLR agonists for chronic hepatitis $C$ infection}

As treatment for $\mathrm{HCV}$ is slowly evolving from an immune based interferon-containing therapy to an interferon-free, all oral, directly acting antiviral (DAA) therapy, much more needs to be learned about the correlates of $\mathrm{HCV}$ clearance. Induction of hepatic type I interferons seems to be a reliable early indicator of sustained virologic response to DAA-based therapies [49]. In this regard, HCV therapy can be optimized by enhancing an endogenous hepatic interferon response by using TLR agonists. Hence, the evaluation of novel immunomodulatory strategies, such as the use of TLR7 agonists, which result in an induction of endogenous type I interferon response, is warranted in maximizing the effectiveness of HCV therapeutics.

In a proof of concept study isatoribine, a TLR7 agonist, was shown to cause a significant reduction of plasma HCV RNA in previously untreated $\mathrm{HCV}$-infected individuals [50]. Administration of the TLR7 agonist isatoribine was shown to significantly increase viral clearance by inducing an immune antiviral response, as indicated by dose-dependent changes in immunologic biomarkers [50]. Treatment was well tolerated and viral reduction occurred in both genotype 1 and non-genotype $1 \mathrm{HCV}$ infection [50]. Since this initial trial, small-molecule TLR7 agonists have become a focus of clinical trials for the treatment of chronic $\mathrm{HCV}$ infection. In a multi-center, phase IIa study, resiquimod, a TLR7/8 agonist was taken orally for 4 weeks resulted in a transient viral reduction, but serious adverse events were reported consistent with IFN- $\alpha$ induction, including fever, headache, shivering and lymphopenia [51]. As a result of the systemic effects of the drug, resiquimod was withdrawn from clinical testing for HCV but was further examined as a topical agent for HPV [52]. Another agent, PF-4878691, effectively induced immune biomarkers and IFN responses in a dose-dependent manner, but its antiviral effect was only produced at doses associated with serious adverse events [53,54]. An oral isatoribine prodrug, ANA773, was administered to $\mathrm{HCV}$-infected patients every other day for 28 days (800 mg, $1200 \mathrm{mg}$, or $1600 \mathrm{mg}$ ) or for 10 days (2000 mg). A significant reduction of serum HCV RNA levels was seen in the $2000 \mathrm{mg}$-dosed group. The drug was generally well tolerated and most of the reported adverse events symptoms disappeared rapidly during continued dosing, resulting in no dose reductions or discontinuations. Thus, ANA773 is the first oral TLR7 agonist to induce a dose-related antiviral response leading to a significant decrease in serum HCV RNA levels without the concurrent induction of prohibitive systemic side effects [55]. Hence, it is plausible that viral eradication may be enhanced using a strategy that optimally targets the host innate immune system by using an oral selective TLR7 agonist to induce a direct antiviral effect (type I interferon signature) and an indirect effect (enhancing HCV-specific immunity by cross-linking innate and adaptive immune system), resulting in rapid eradication of $\mathrm{HCV}$ without a myriad of adverse events.

\section{Hepatitis B infection}

Hepatitis B (HBV) is an enveloped, double stranded DNA virus that can be transmitted perinatally, percutaneously, or through close person-to-person contact [56]. An estimated 350 million individuals are chronically infected with hepatitis B worldwide [57], with approximately 1.25 million HBV carriers living in the United States $[56,58]$. HBV carriers are at an increased risk of liver damage, including cirrhosis, hepatic decompensation and hepatocellular carcinoma $[59,60]$. Hepatitis B virus is self-limited in $90-95 \%$ of adults. The remainder will develop chronic hepatitis $B$ infection, as demonstrated by the presence of $\mathrm{HBsAg+}$, serum HBV DNA, persistent or intermittent elevation in ALT/AST levels and evidence of necroinflammation.

\section{Treatment for HBV}

The current goal of chronic hepatitis B treatment is to achieve long lasting suppression of HBV replication to prevent cirrhosis, hepatic failure and HCC. Currently, immune based treatment of chronic HBV infection consists of IFN administration. Nucleoside analogues (NA), mainly tenofovir and entecavir, can achieve long-term suppression of HBV. Complete response to treatment, also known as HBV clearance, consists of an HBsAg seroconversion, normalization of ALT/AST, absence of serum HBV DNA and absence of covalently closed circular DNA (ccDNA). Complete response is rare with the use of NA alone, but can be rarely achieved through the use of immune-based therapy, or via rare spontaneous clearance. In the absence of a cure, long-term suppression of HBV is required to prevent progression of liver disease. However, long-term suppressive therapy with NA is associated with emergence of resistance and toxicities [61]. Some nucleoside analogues have a low barrier to resistance and once antiviral-resistant HBV mutants are selected they are typically retained in the virus population indefinitely [62]. Even in the setting of successful viral suppression and normal ALT/AST levels, it is uncertain what long-term risk of sequelae like HCC is in 
these patients. Although chronic HBV infection may be cleared without induction of innate immune responses [63] there is proof of principle data available that immunebased treatment such as interferon- $\alpha$ is capable of achieving protective immunity in some treated patients [64]. This offers hope that similar strategies, that are safer, more tolerated and orally available could be vital in accomplishing a "functional cure" of HBV.

\section{TLR agonists for chronic hepatitis $B$ infection}

Studies have shown that liver of HBV transgenic mice produce IFN- $\alpha,-\beta$ and $-\gamma$ to inhibit hepatitis $B$ replication, suggesting that HBV replication can be controlled by activation of innate immune response in the liver [65] When HBV transgenic mice were injected with ligands specific for TLR 2 through 9, HBV replication was nearly eliminated after a single injection of $10 \mu \mathrm{g}$ of each ligand except for TLR2 ligands. The inhibition of HBV replication was essentially noninflammatory and noncytopathic and was accompanied by the induction of IFN- $\alpha$ and IFN- $\beta$ [65]. The inhibition of HBV replication was accomplished at a posttranscriptional level by suppressing the assembly or stability of HBV RNA-containing capsids, where HBV DNA synthesis is known to occur $[65,66]$. These findings provide evidence that TLR activation directly inhibits HBV replication $[18,67]$. However, HBV may evade innate recognition by TLRs as a strategy to escape the innate immune response by disrupting TLR expression, resulting in inhibition of TLR signaling cascades $[18,67]$. It has been reported that the expression of TLRs in hepatocytes and other cells is down regulated in the presence various HBV viral products [68-73]. Although HBV circumvents endogenous type I interferon pathways, it is plausible that exogenous interferon induction by using a TLR7 agonist may reinstate interferon- $\alpha$ responses. When combined with a strategy that results in maximal suppression of HBV replication in vivo using NAs, exogenous IFN stimulation via TLR agonists may result in development of protective immunity. Several studies have shown that long-term suppression of HBV using NAs results in partial reconstitution of adaptive immunity. Furthermore, TLR7 mediated signaling may also contribute to adaptive immune responses [12]. In this regard, an adjuvant therapy using a TLR agonist may be able to accelerate this process of immune reconstitution and aid in functional cure or HBsAg seroconversion both by innate and adaptive immune signaling.

There are other potential benefits in the use of TLR agonists for treatment of chronic HBV infection. First, TLR agonists are available as oral compounds enabling rapid uptake by liver. Pre-systemic activation by TLR agonists via gut absorption into portal circulation may allow for optimal, lower doses of adjuvant therapy to minimize adverse events. Second, they may be co-formulated with other NAs as a single pill. Third, TLR7 agonists are selective and do not activate the TLR8 pathway, thus eliminating the negative affects of TNF- $\alpha$ activation. Finally, similar to injected IFN, TLR agonists induce IFN production, triggering the production of cytokines to facilitate intracellular communication and cellular trafficking. However, through the use of TLR agonists this antiviral state can be induced at the local level, pre-systemically rather than systemically, eliminating the adverse events associated with systemic innate immune activation.

Recent studies have shown that TLR7 agonist administration results in an augmentation of downstream signaling of interferon stimulated genes (ISGs) without systemic IFN- $\alpha$ related adverse events. In particular, the induction of ISG15 and CCL 8 mRNA have been implicated as markers of presystemic immune response in response to TLR7 agonist stimulation [74]. Recently, in chronically infected chimpanzees, GS-9620, a selective oral agonist of TLR7, induced prolonged suppression of HBV DNA in both the serum and liver [75]. GS-9620 administration induced the production of IFN- $\alpha$ and various cytokines and chemokines. In addition, it activated all lymphocyte subsets to induce ISGs [75]. HBV DNA was reduced in addition to serum levels of HBsAg, HBeAg and HBV antigen positive hepatocytes [75]. In early studies of oral GS-9620 in healthy volunteers, oral doses (single dose of $0.3,1,2,3,4,6,8$, or $12 \mathrm{mg}$ ) were well absorbed and well tolerated in doses up to $12 \mathrm{mg}$. Adverse events associated with IFN treatment were seen subjects who received $8 \mathrm{mg}$ or $12 \mathrm{mg}$ dose and serum IFN- $\alpha$ was only detected at these doses although activation or ISGs were seen at doses $\geq 2 \mathrm{mg}$ [76].

\section{Conclusions}

Optimal induction of innate and adaptive immunity contribute to host defenses against viral pathogens such as hepatitis B and C. Endogenous induction of type I IFNs contributes to the clearance of these viruses, hence the appeal of selective TLR7 agonists, which generate endogenous type I interferons and could thus aid in augmenting spontaneous and therapeutic clearance of hepatitis viruses. Adjunctive treatment with such agents may allow for shorter, less toxic, and less expensive courses of antiviral therapy. This approach, if successful, will have a tremendous impact on the public health burden of chronic liver diseases, wherein HCC and death due $\mathrm{HCV}$ and $\mathrm{HBV}$ infections are common.

\section{Abbreviations}

TLR: Toll-like receptors; PRR: Pattern recognition receptor; HBV: Hepatitis B virus; HCV: Hepatitis C virus; PAMP: Pathogen associated molecular patterns; IL: Interleukin; TIR: Toll/interleukin-1 receptor; MyD88: Myeloid differentiation primary-response protein; IRAKs: IL-1R associated kinases; TNFR: Tumor necrosis factor receptor; TRAF6: TNFR-associated factor 6; TGF-B: Transforming growth factor B; TAK1: TGF-B activated kinase; NF-KB: Nuclear factor kappa B; IFR7: IFN regulatory factor 7; TNF-a: Tumor necrosis factor alpha; MHC: Major histocompatibility complex; APC: Antigen presenting cell; pDC: Plasmacytoid dendritic cell; mDC: Myeloid dendritic cell; IFN: Interferon; $T_{H} 1$ : Type 1 T helper cells; SVR: Sustained virologic response; ISG: Interferon stimulated genes; 
RIG-1: Retinoic acid inducible gene 1; HBsAg: Hepatitis B s antigen; NA: Nucleoside analogues; HCC: Hepatocellular carcinoma; HBeAg: Hepatitis B e antigen; DAA: directly acting antiviral.

\section{Competing interests}

The authors declare that they have no competing interests.

\section{Authors' contributions}

EF performed literature search, wrote the primary manuscript, SK and BG assisted with concept and design of the manuscript, proof read the manuscript and RT designed the manuscript concept and wrote the manuscript. All authors read and approved the final manuscript.

\section{Acknowledgment}

This research was supported by the Intramural Research Program of the $\mathrm{NIH}$ (National Institute of Allergy and Infectious Diseases, and the Clinical Research Center). The content of this publication does not necessarily reflect the views or policies of the Department of Health and Human Services, nor does mention of trade names, commercial products, or organizations imply endorsement by the U.S. Government.

\section{Disclaimer}

The content of this publication does not necessarily reflect the views of policies of the Department of Health and Human Services, nor does mention of trade names, commercial products or organizations imply endorsement by the U.S. Government.

\section{Author details}

${ }^{1}$ Critical Care Medicine Department, Clinical Research Center, National Institutes of Health, Bethesda, MD 20892, USA. ${ }^{2}$ Laboratory of Immunoregulation, National Institute of Allergy and Infectious Diseases, National Institutes of Health, Bethesda, MD 20892, USA. ${ }^{3}$ Institute of Human Virology at the University of Maryland School of Medicine, 725 West Lombard St. N151, Baltimore, MD 21201, USA.

Received: 7 January 2014 Accepted: 16 April 2014

Published: 14 May 2014

\section{References}

1. Iwasaki A, Medzhitov R: Regulation of adaptive immunity by the innate immune system. Science 2010, 327:291-295.

2. Akira S, Takeda K: Toll-like receptor signalling. Nat Rev Immunol 2004, 4:499-511.

3. Janeway CA Jr, Medzhitov R: Innate immune recognition. Annu Rev Immunol 2002, 20:197-216.

4. Medzhitov R: Toll-like receptors and innate immunity. Nat Rev Immunol 2001, 1:135-145.

5. Aderem A, Ulevitch RJ: Toll-like receptors in the induction of the innate immune response. Nature 2000, 406:782-787.

6. Wu J, Lu M, Meng Z, Trippler M, Broering R, Szczeponek A, Krux F, Dittmer U, Roggendorf M, Gerken G, Schlaak JF: Toll-like receptor-mediated control of HBV replication by nonparenchymal liver cells in mice. Hepatology 2007, 46:1769-1778.

7. Rehermann B, Nascimbeni M: Immunology of hepatitis B virus and hepatitis C virus infection. Nat Rev Immunol 2005, 5:215-229.

8. Talwani R, Gilliam BL, Rizza SA, Nehra V, Temesgen Z: Current status of treatment for chronic hepatitis C virus infection. Drugs Today (BarC) 2012, 48:219-231.

9. Falck-Ytter Y, Kale H, Mullen KD, Sarbah SA, Sorescu L, McCullough AJ: Surprisingly small effect of antiviral treatment in patients with hepatitis $C$. Ann Intern Med 2002, 136:288-292.

10. Robek MD, Wieland SF, Chisari FV: Inhibition of hepatitis B virus replication by interferon requires proteasome activity. J Virol 2002, 76:3570-3574.

11. Janeway CA Jr, Medzhitov R: Introduction: the role of innate immunity in the adaptive immune response. Semin Immunol 1998, 10:349-350.

12. Iwasaki A, Medzhitov R: Toll-like receptor control of the adaptive immune responses. Nat Immunol 2004, 5:987-995.

13. Akira $\mathrm{S}$, Uematsu $\mathrm{S}$, Takeuchi O: Pathogen recognition and innate immunity. Cell 2006, 124:783-801.
14. Sioud M: Innate sensing of self and non-self RNAs by Toll-like receptors. Trends Mol Med 2006, 12:167-176.

15. West AP, Koblansky AA, Ghosh S: Recognition and signaling by toll-like receptors. Annu Rev Cell Dev Biol 2006, 22:409-437.

16. Prinz M, Heikenwalder M, Schwarz P, Takeda K, Akira S, Aguzzi A: Prion pathogenesis in the absence of Toll-like receptor signalling. EMBO Rep 2003, 4:195-199.

17. Alexopoulou L, Holt AC, Medzhitov R, Flavell RA: Recognition of double-stranded RNA and activation of NF-kappaB by Toll-like receptor 3. Nature 2001, 413:732-738.

18. Schwabe RF, Seki E, Brenner DA: Toll-like receptor signaling in the liver. Gastroenterology 2006, 130:1886-1900.

19. Diebold SS, Kaisho T, Hemmi H, Akira S, Reis e Sousa C: Innate antiviral responses by means of TLR7-mediated recognition of single-stranded RNA. Science 2004, 303:1529-1531.

20. Lund JM, Alexopoulou L, Sato A, Karow M, Adams NC, Gale NW, Iwasaki A Flavell RA: Recognition of single-stranded RNA viruses by Toll-like receptor 7. Proc Natl Acad Sci U S A 2004, 101:5598-5603.

21. Hemmi H, Takeuchi O, Kawai T, Kaisho T, Sato S, Sanjo H, Matsumoto M, Hoshino K, Wagner H, Takeda K, Akira S: A Toll-like receptor recognizes bacterial DNA. Nature 2000, 408:740-745.

22. Baccarella A, Fontana MF, Chen EC, Kim CC: Toll-like receptor 7 mediates early innate immune responses to malaria. Infect Immun 2013, 81:4431-4442.

23. McGilvray I, Feld JJ, Chen L, Pattullo V, Guindi M, Fischer S, Borozan I, Xie G, Selzner N, Heathcote EJ, Siminovitch K: Hepatic cell-type specific gene expression better predicts HCV treatment outcome than IL28B genotype. Gastroenterology 2012, 142:1122-1131. e1121.

24. Lee MS, Kim YJ: Signaling pathways downstream of pattern-recognition receptors and their cross talk. Annu Rev Biochem 2007, 76:447-480.

25. Gay NJ, Gangloff M: Structure and function of Toll receptors and their ligands. Annu Rev Biochem 2007, 76:141-165.

26. Banchereau J, Steinman RM: Dendritic cells and the control of immunity. Nature 1998, 392:245-252.

27. Schnare M, Barton GM, Holt AC, Takeda K, Akira S, Medzhitov R: Toll-like receptors control activation of adaptive immune responses. Nat Immunol 2001, 2:947-950.

28. Lanier LL, O'Fallon S, Somoza C, Phillips JH, Linsley PS, Okumura K, Ito D, Azuma M: CD80 (B7) and CD86 (B70) provide similar costimulatory signals for $\mathrm{T}$ cell proliferation, cytokine production, and generation of $\mathrm{CTL}$. $\mathrm{J}$ Immunol 1995, 154:97-105.

29. Asselin-Paturel C, Brizard G, Chemin K, Boonstra A, O'Garra A, Vicari A, Trinchieri G: Type I interferon dependence of plasmacytoid dendritic cell activation and migration. J Exp Med 2005, 201:1157-1167.

30. Seki E, Brenner DA: Toll-like receptors and adaptor molecules in liver disease: update. Hepatology 2008, 48:322-335.

31. Akira S, Takeda K, Kaisho T: Toll-like receptors: critical proteins linking innate and acquired immunity. Nat Immunol 2001, 2:675-680.

32. Shu SA, Lian ZX, Chuang YH, Yang GX, Moritoki Y, Comstock SS, Zhong RQ, Ansari AA, Liu YJ, Gershwin ME: The role of CD11C(+) hepatic dendritic cells in the induction of innate immune responses. Clin Exp Immunol 2007, 149:335-343.

33. Trinchieri G: Interleukin-12 and the regulation of innate resistance and adaptive immunity. Nat Rev Immunol 2003, 3:133-146.

34. Takeda K, Kaisho T, Akira S: Toll-like receptors. Annu Rev Immunol 2003, 21:335-376.

35. Kaisho T, Takeuchi O, Kawai T, Hoshino K, Akira S: Endotoxin-induced maturation of MyD88-deficient dendritic cells. J Immunol 2001, 166:5688-5694.

36. Ito T, Amakawa R, Kaisho T, Hemmi H, Tajima K, Uehira K, Ozaki Y, Tomizawa H, Akira S, Fukuhara S: Interferon-alpha and interleukin-12 are induced differentially by Toll-like receptor 7 ligands in human blood dendritic cell subsets. J Exp Med 2002, 195:1507-1512.

37. Armstrong GL, Wasley A, Simard EP, McQuillan GM, Kuhnert WL, Alter MJ: The prevalence of hepatitis C virus infection in the United States, 1999 through 2002. Ann Intern Med 2006, 144:705-714.

38. Ghany MG, Strader DB, Thomas DL, Seeff LB: Diagnosis, management, and treatment of hepatitis C: an update. Hepatology 2009, 49:1335-1374.

39. Alter MJ, Margolis HS, Krawczynski K, Judson FN, Mares A, Alexander WJ, Hu PY, Miller JK, Gerber MA, Sampliner RE, Meeks EL, Beach MJ: The natural history of community-acquired hepatitis $C$ in the United States. The Sentinel Counties Chronic non-A, non-B Hepatitis Study Team. N Engl J Med 1992, 327:1899-1905. 
40. Rustgi VK: The epidemiology of hepatitis $C$ infection in the United States. J Gastroenterol 2007, 42:513-521.

41. Di Bisceglie AM: Natural history of hepatitis C: its impact on clinical management. Hepatology 2000, 31:1014-1018.

42. Lavanchy D: Evolving epidemiology of hepatitis C virus. Clin Microbiol Infect 2011, 17:107-115.

43. Kim WR, Terrault NA, Pedersen RA, Therneau TM, Edwards E, Hindman AA, Brosgart CL: Trends in waiting list registration for liver transplantation for viral hepatitis in the United States. Gastroenterology 2009, 137:1680-1686.

44. American Association for the Study of Liver Diseases (AASLD) and Infectious Diseases Society of America (IDSA) Recommendations for Testing, Managing and Treating Hepatitis C. http://www.hcvguidelines.org Accessed April 21, 2014.

45. Lawitz E, Mangia A, Wyles D, Rodriguez-Torres M, Hassanein T, Gordon SC, Schultz M, Davis MN, Kayali Z, Reddy KR, Jacobson IM, Kowdley KV, Nyberg L, Subramanian GM, Hyland RH, Arterburn S, Jiang D, McNally J, Brainard D, Symonds WT, McHutchinson JG, Sheikh AM, Younossi Z, Gane EJ: Sofosbuvir for previously untreated chronic hepatitis C infection. N Engl J Med 2013, 368:1878-1887.

46. Rehermann B: Hepatitis $C$ virus versus innate and adaptive immune responses: a tale of coevolution and coexistence. J Clin Invest 2009, 119:1745-1754.

47. Narita M, Watanabe N, Yamahira A, Hashimoto S, Tochiki N, Saitoh A, Kaji M, Nakamura T, Furukawa T, Toba K, Fuse I, Aizawa Y, Takahashi M: A leukemic plasmacytoid dendritic cell line, PMDC05, with the ability to secrete IFN-alpha by stimulation via Toll-like receptors and present antigens to naive T cells. Leuk Res 2009, 33:1224-1232.

48. Zhang S, Kodys K, Babcock GJ, Szabo G: CD81/CD9 tetraspanins aid plasmacytoid dendritic cells in recognition of hepatitis $C$ virus-infected cells and induction of interferon-alpha. Hepatology 2013, 58:940-949.

49. Meissner EGOA, Polis MA, Kottilil S: Intrahepatic Changes in the Endogenous Interferon Response are Associated with SVR in Chronic Hepatitis C, Genotype-1 Subjects Treated with Sofosbuvir and Ribavirin. Washington, D.C.: In American Association for the Study of Liver Diseases; 2013.

50. Horsmans Y, Berg T, Desager JP, Mueller T, Schott E, Fletcher SP, Steffy KR, Bauman LA, Kerr BM, Averett DR: Isatoribine, an agonist of TLR7, reduces plasma virus concentration in chronic hepatitis C infection. Hepatology 2005, 42:724-731.

51. Pockros PJ, Guyader D, Patton H, Tong MJ, Wright T, McHutchison JG, Meng TC: Oral resiquimod in chronic HCV infection: safety and efficacy in 2 placebo-controlled, double-blind phase lla studies. J Hepatol 2007 47:174-182

52. Meyer T, Surber C, French LE, Stockfleth E: Resiquimod, a topical drug for viral skin lesions and skin cancer. Expert Opin Investig Drugs 2013, 22:149-159.

53. Harrison LI, Astry C, Kumar S, Yunis C: Pharmacokinetics of 852A, an imidazoquinoline Toll-like receptor 7-specific agonist, following intravenous, subcutaneous, and oral administrations in humans. J Clin Pharmacol 2007, 47:962-969.

54. Fidock MD, Souberbielle BE, Laxton C, Rawal J, Delpuech-Adams O, Corey TP, Colman P, Kumar V, Cheng JB, Wright K, Srinivasan S, Rana K, Craig C, Horscroft $\mathrm{N}$, Perros M, Westby IM, Webster $R$, van der Ryst E: The innate immune response, clinical outcomes, and ex vivo HCV antiviral efficacy of a TLR7 agonist (PF-4878691). Clin Pharmacol Ther 2011, 89:821-829.

55. Bergmann JF, de Bruijne J, Hotho DM, de Knegt RJ, Boonstra A, Weegink CJ, van Vliet AA, van de Wetering J, Fletcher SP, Bauman LA, Rahimy M, Appleman JR, Freddo JL, Janssen HL, Reesink HW: Randomised clinical trial: anti-viral activity of ANA773, an oral inducer of endogenous interferons acting via TLR7, in chronic HCV. Aliment Pharmacol Ther 2011, 34:443-453.

56. Mast EE, Margolis HS, Fiore AE, Brink EW, Goldstein ST, Wang SA, Moyer LA, Bell BP, Alter MJ: A comprehensive immunization strategy to eliminate transmission of hepatitis B virus infection in the United States: recommendations of the Advisory Committee on Immunization Practices (ACIP) part 1: immunization of infants, children, and adolescents. MMWR Recomm Rep 2005, 54:1-31.

57. Lavanchy D: Hepatitis B virus epidemiology, disease burden, treatment, and current and emerging prevention and control measures. J Viral Hepat 2004, 11:97-107.

58. McQuillan GM, Coleman PJ, Kruszon-Moran D, Moyer LA, Lambert SB, Margolis HS: Prevalence of hepatitis B virus infection in the United States: the National Health and Nutrition Examination Surveys, 1976 through 1994. Am J Public Health 1999, 89:14-18.
59. Beasley RP: Hepatitis B virus. The major etiology of hepatocellular carcinoma Cancer 1988, 61:1942-1956.

60. Bosch FX, Ribes J, Cleries R, Diaz M: Epidemiology of hepatocellular carcinoma. Clin Liver Dis 2005, 9:191-211. v.

61. Lok AS, McMahon BJ: Chronic hepatitis B: update 2009. Hepatology 2009, 50:661-662.

62. Yim HJ, Hussain M, Liu Y, Wong SN, Fung SK, Lok AS: Evolution of multi-drug resistant hepatitis $B$ virus during sequential therapy. Hepatology 2006, 44:703-712.

63. Wieland S, Thimme R, Purcell RH, Chisari FV: Genomic analysis of the host response to hepatitis B virus infection. Proc Natl Acad Sci U S A 2004, 101:6669-6674.

64. Lampertico P, Del Ninno E, Manzin A, Donato MF, Rumi MG, Lunghi G, Morabito A, Clementi M, Colombo M: A randomized, controlled trial of a 24-month course of interferon alfa $2 b$ in patients with chronic hepatitis $B$ who had hepatitis B virus DNA without hepatitis B e antigen in serum. Hepatology 1997, 26:1621-1625.

65. Isogawa M, Robek MD, Furuichi Y, Chisari FV: Toll-like receptor signaling inhibits hepatitis B virus replication in vivo. J Virol 2005, 79:7269-7272.

66. Wieland SF, Guidotti LG, Chisari FV: Intrahepatic induction of alpha/beta interferon eliminates viral RNA-containing capsids in hepatitis B virus transgenic mice. J Virol 2000, 74:4165-4173.

67. Zhang X, Kraft A, Broering R, Schlaak JF, Dittmer U, Lu M: Preclinical development of TLR ligands as drugs for the treatment of chronic viral infections. Expert Opin Drug Discov 2012, 7:597-611.

68. Visvanathan K, Skinner NA, Thompson AJ, Riordan SM, Sozzi V, Edwards R, Rodgers S, Kurtovic J, Chang J, Lewin S, Desmond P, Locarnini S: Regulation of Toll-like receptor- 2 expression in chronic hepatitis $B$ by the precore protein. Hepatology 2007, 45:102-110.

69. Lang T, Lo C, Skinner N, Locarnini S, Visvanathan K, Mansell A: The hepatitis $\mathrm{B}$ e antigen $(\mathrm{HBeAg})$ targets and suppresses activation of the toll-like receptor signaling pathway. J Hepatol 2011, 55:762-769.

70. Chen Z, Cheng Y, Xu Y, Liao J, Zhang X, Hu Y, Zhang Q, Wang J, Zhang Z, Shen $F$, Yuan Z: Expression profiles and function of Toll-like receptors 2 and 4 in peripheral blood mononuclear cells of chronic hepatitis $B$ patients. Clin Immunol 2008, 128:400-408.

71. Wang $H$, Ryu WS: Hepatitis B virus polymerase blocks pattern recognition receptor signaling via interaction with DDX3: implications for immune evasion. PLoS Pathog 2010, 6:e1000986.

72. Yu S, Chen J, Wu M, Chen H, Kato N, Yuan Z: Hepatitis B virus polymerase inhibits RIG-I- and Toll-like receptor 3-mediated beta interferon induction in human hepatocytes through interference with interferon regulatory factor 3 activation and dampening of the interaction between TBK1/IKKepsilon and DDX3. J Gen Virol 2010, 91:2080-2090.

73. Wu J, Meng Z, Jiang M, Pei R, Trippler M, Broering R, Bucchi A, Sowa JP, Dittmer U, Yang D, Roggendorf M, Gerken G, Lu M, Schlaak JF: Hepatitis B virus suppresses toll-like receptor-mediated innate immune responses in murine parenchymal and nonparenchymal liver cells. Hepatology 2009, 49:1132-1140.

74. Gane EJSE, Gordon SC, Gruener D: Safety and Pharmacodynamics of Oral TLR-7 agonist GS-9620 in patients with Chronic Hepatitis B. Washington DC: American Association for the Study of Liver Disease; 2013.

75. Lanford RE, Guerra B, Chavez D, Giavedoni L, Hodara VL, Brasky KM, Fosdick A, Frey CR, Zheng J, Wolfgang G, Halcomb RL, Tumas DB: GS-9620, an oral agonist of Toll-like receptor-7 induces prolonged suppression of Hepatitis B Virus in chronically infected chimpanzees. Gastroenterology 2013, 144:1508-1517.

76. Lopatin U, Wolfgang G, Tumas D, Frey CR, Ohmstede C, Hesselgesser J, Kearney B, Moorehead L, Subramanian GM, McHutchison JG: Safety, pharmacokinetics and pharmacodynamics of GS-9620, an oral Toll-like receptor 7 agonist. Antivir Ther 2013, 18:409-418.

doi:10.1186/1479-5876-12-129

Cite this article as: Funk et al:: Tickling the TLR7 to cure viral hepatitis. Journal of Translational Medicine 2014 12:129. 